\title{
Private Transfer Choices under Uncertainty in Human Capital
}

\author{
Rodrigo J. Raad ${ }^{\dagger}$, Gilvan R. Guedes ${ }^{\dagger}$
}

Sumário: 1. Introduction; 2. Motives for private transfer; 3. The model; 4. Empirical Analysis; 5. Results; 6. Conclusion; A. Appendix.

Palavras-chave: Land inheritance, Altruism, Exchange motive, Nash equilibrium, Brazilian Amazon.

Códigos JEL: $\quad$ C72, C01, D13, D64, R29.

We develop a theoretical model for parental behavior regarding land inheritance, accounting for consumption and savings strategies. We identify two types of modeling: one with, and another without, strategic behavior. In the first model, we assume that children do not act strategically towards their parent. We find that the child with the highest return to human capital is more likely to receive a larger share of the land if the difference in offspring's returns is large. In the second model, we allow for each child to influence parent's optimal choice of bequest by providing services to the latter. We illustrate that the child's strategy for service provision is sufficient to assure that the one providing more assistance will receive a larger share of the bequest in a Nash equilibrium. We conclude by illustrating our theoretical model with some empirical analysis using longitudinal data for the rural Brazilian Amazon.

Este trabalho apresenta um modelo teórico para o comportamento dos pais em relação à transferência de seu patrimônio rural para os filhos, levando em conta estratégias de consumo e investimento. Identificamos dois tipos de modelagem, incluindo ou não um comportamento estratégico na família. No primeiro modelo, assumimos que os filhos não se comportam estrategicamente em relação aos pais. Neste caso, mostramos que ofilho com o maior retorno em capital humano é mais propenso a receber uma parcela maior da herança se a diferença nos retornos em capital humano entre os irmãos é grande. No segundo modelo, permitimos que cada filho influencie a escolha ótima de transferência de herança através do provimento de serviços aos pais. Ilustramos, através de uma simulação numérica, que é possivel que o filho com maior comprometimento com relação à assistência aos pais receberá a maior parte da herança em um equilíbrio de Nash, mesmo que tenha um capital humano inferior. Concluímos, ilustrando o nosso modelo teórico através de uma análise empírica baseada em dados longitudinais coletados na Amazônia rural brasileira.

\footnotetext{
*This research was supported by CAPES (Coordenação de Aperfeiçoamento de Pessoal de Nível Superior), FAPEMIG (Fundação de Amparo à Pesquisa do Estado de Minas Gerais) and CNPQ (Conselho Nacional de Desenvolvimento Científico e Tecnológico).

${ }^{\dagger}$ Department of Economics-Federal University of Minas Gerais. Av. Antônio Carlos, 6627, Pampulha, Belo Horizonte, MG, Brazil. CEP 31270-901. E-mail: rjraad@gmail.com

${ }^{\ddagger}$ Department of Demography-Federal University of Minas Gerais. Av. Antônio Carlos, 6627, Pampulha, Belo Horizonte, MG, Brazil. CEP 31270-901. Tel. +55313409 7165. FAX: +55313409 7203. E-mail: grguedes@cedeplar.ufmg.br
} 


\section{INTRODUCTION}

The study of income transfers within a family is of great interest to the literature on economic demography. Private transfers act as a way to improve the well-being of individuals, either by smoothing or increasing inequality among family members (Becker \& Tomes, 1979; Tomes, 1981). Thus, both the amount and the rule of parental investment have intergenerational consequences on wealth accumulation (Keister, 2003). It can also influence the effectiveness of government redistribution depending on an agent's motives (Altonji, Hayashi, \& Kotlikoff, 1997; Barro, 1974; Cox \& Jakubson, 1995; Lee \& Mason, 2010). Finally, because family members can enter into a contractual arrangement for mutual risk smoothing, private transfers may reduce aggregate market insurance and interest rates (VanWey, 2004).

In this paper, we focus on how parents transfer wealth to their children, mainly in the form of bequests. We assume that children have varying relative skills, yielding different returns to their investment in land-specific human capital. Parents then value this random return in their decision on how much to bequeath. We develop a theoretical model in which agents live for two periods in an environment where wealth transfers between two consecutive periods are available. In the first period, children save to invest in land-specific human capital ${ }^{1}$ characterized by specific skills, such as training on how to grow perennials or how to raise cattle. In the second period, income from job specialization generates returns to the previous investment in land-specific human capital as in Baker and Micelli (2005).

Our theoretical model also contemplates the situation where children provide services to their parents. Uncertainty in the first period is a consequence of differences among children's relative abilities. To model this uncertainty, we use the concept of subjective probability as in Savage (1964), which consists of assigning a subjective probability distribution for the returns in the second period. These probability distributions can differ among children and are of common knowledge within the family. A risk-free asset with known return is available at the initial period, which allows parents to save wealth for the next period. For the sake of simplicity, we assume that all family members live for two periods and that parents transfer a part of the total wealth. Therefore, we assume that parents consume the remaining goods by their death, in contrast to Bernheim and Severinov (2003). Without loss of generality, we suppose that all bequeatable wealth is represented by intended bequests. Finally, we assume that children do not invest in the second period, with all surviving to be eligible as heirs.

In particular, we consider two different approaches. In the first approach, the parent makes transfers in the second period and no strategic behavior from the children arises. The lack of strategic behavior holds because children do not provide any good or service valued by the parent. As an important result, we provide conditions on the primitives of the model to show that the child with the highest subjective return to land-specific human capital receives the largest share of total bequest. In the second approach, each child may provide a good or service as a way to alter their parents' optimal choice for bequests. As in Baker and Micelli (2005), all family members are in a sequential move game in which each child strategically chooses to invest in land-specific human capital. Furthermore, the parent strategy consists in establishing a sharing rule for the bequest. In contrast to Baker and Micelli (2005), we consider that children's consumption ${ }^{2}$ directly affects the parent's preference. In addition, the sharing rule for the bequeatable wealth is endogenously defined, contrary to Baker and Micelli (2005). We exhibit a numerical example showing that the lowest return child can supply additional levels of services to compensate for a parent's predisposition to transfer a higher share to the most productive child.

The literature on transfers usually contemplates two major types of motives: altruistic (Altonji et al., 1997; Becker, 1974; Becker \& Tomes, 1979; McGarry, 1999; Stark \& Zhang, 2002) and exchange (Bernheim, Shleifer, \& Summers, 1985; Chang, 2007). The first approach focuses on how parents use transfers to smooth the consumption of needed family members. The second approach considers the transfer as a way to induce the behavior of beneficiaries who provide services of interest. Altonji et al. (1997) define

\footnotetext{
${ }^{1}$ Measured in units of the consumption good and represented by the opportunity cost of alternative paid activities.

${ }^{2}$ And not only children's land-specific production.
} 
the economic perfect altruism whether an increase by one dollar in the income of parents actively making transfers to a child coupled with a one-dollar reduction in that child's income results in the parents' increasing their transfer to the child by one dollar. We use a parsimonious definition of altruism by considering that the parent is altruist when he seeks to smooth offsprings' wealth. The theoretical literature on private transfers is majorly in tandem with non-altruistic behavior (Altonji et al., 1997; Baker \& Micelli, 2005; Bernheim et al., 1985), although some alternative arguments in favor of indirect altruism ${ }^{3}$ exist (McGarry, 1999; Stark \& Zhang, 2002). Empirical literature on transfer motives has provided mixed evidence on both altruistic and strategic behavior (VanWey, 2004). The non-consensual empirical support is mainly explained by data quality, sample size in highly demanding asymptotic estimation procedures, and the difference in how transfers are measured.

Baker and Micelli (2005) propose a model of land inheritance based on strategic behavior. Their model considers a production function including children's random relative skills and stocks of landspecific human capital. Differing from typical altruistic models of transfers, parents do not take into account the well-being of children. The model considers a simultaneous move game yielding results under a Nash equilibrium and does not include wealth transfers over consecutive periods. The authors find that children overinvest in land-specific human capital when compared to equal sharing.

\section{MOTIVES FOR PRIVATE TRANSFER}

The effects of private transfers on the well-being of individuals and their relations to public transfers are directly linked to the reasons for why individuals engage in passing on wealth to others within the family. In general, there are two major motives for familial transfers: altruism (Altonji et al., 1997; Becker, 1974; McGarry, 1999) and exchange motive (Bernheim et al., 1985; Cox, 1987). We describe briefly each one of these models and discuss their strengths and limitations.

The original altruism model (Becker, 1974) assumes that an unselfish individual's utility function is directly affected by his/her own consumption level and by the well-being of others cared about by this individual. The altruistic individual can adjust his/her behavior if close relatives suffer any change in their well-being. The model predicts that altruistic parents try to equalize utility levels across their offspring, making the largest transfer to the least well-off child. Moreover, if altruism is operative, it should lead to the Ricardian equivalence, crowding out the effect of public transfers (Barro, 1974).

Under the traditional altruistic models, an increase in a child's pre-transfer income reduces the parents' marginal utility of making a transfer to that child. Thus, we expect a negative relationship between the incidence of transfers and the recipient's pre-transfer income under the altruism hypothesis. However, Altonji et al. (1997) and McGarry (1999) argue that this relation depends on the kind of transfer. Inter vivos transfers should be negatively associated to a child's current income because lowincome children are considered to be liquidity constrained. Bequests, on the other hand, hold weak (positive in families who make inter vivos transfers) or no (families making no inter vivos transfers) relationship with a child's current income. Stark and Zhang (2002) emphasize that the available empirical evidence is not in agreement with theoretical predictions. They present a model for parents who are equally altruistic towards their children. Their model, however, predicts that parents would actually make the largest transfers to the child whose current income or potential earnings is higher. The key point is that altruistic parents believe that their children are equally altruistic, and as family members are interlinked, indirect transfers between siblings would smooth out direct transfers from parents to children. An optimal choice would be to transfer more to the child with the largest earning potential, because this child would transfer part of the augmented wealth to the less talented sibling. This result holds only if the beneficiary child has a marginal propensity to save sufficiently higher than his/her siblings. The authors, however, do not take this fact into account in their theoretical model of transfers.

\footnotetext{
${ }^{3}$ For instance, Stark and Zhang (2002) assume that larger transfers to children with highest earning capability would be compensated by inter-siblings altruistic transfers.
} 
The exchange motive (Bernheim et al., 1985; Cox, 1987) assumes that parents bequeath as re-payments for services provided by their children at some point. They do so by assigning an ex-ante sharing rule for bequests, directly caring about some actions taken by their children. This direct care establishes the motive for strategic as opposed to nonstrategic influence, as in Becker's rotten kid theorem (Becker, 1974). The model predicts, for instance, that the child who helped the parents more often (with household chores, companionship, or agricultural tasks) would receive the largest transfer or bequest. The transfers profile will be the result of a second best Nash equilibrium among credible beneficiaries in situations where there are at least two recipients. Bernheim, Shleifer, and Summers (1986) generalized this game problem for more than one period. Chang (2007) presents a similar approach using the Nash equilibrium to describe intrahousehold transfers when children provide services for parents. However, the author does not consider the case when children's return to human capital is uncertain. Moreover, the credible threat of parents in transferring unequal bequests is derived exclusively from altruism and not from differences in children's returns to human capital.

Baker and Micelli (2005) develop a theoretical model of land inheritance showing that the knowledge about parents' sharing rules for a bequest affects children's investment in land-specific human capital under some assumptions. The authors argue that in the absence of an uncertainty in future wealth and of a formal land market, fixed inheritance rules prevent wasteful competition among potential heirs for they maximize their investment in land-specific human capital. For example, if the parent decides to leave the largest amount of land to the eldest son (primogeniture), he can invest in agricultural training, thus boosting his productivity.

The existence of a formal land market undermines the fixed inheritance rule because the potential heir could sell the land if this would yield a greater return than its retention (Baker \& Micelli, 2005). This behavior is also affected by ecological conditions. More productive land can induce agents to behave in a way as when a land market is absent; in this situation, land selling is not an optimal choice (Hrdy \& Judge, 1993).

In our study area, there is evidence of a formal land market. VanWey, Guedes, and Dantona (2012) suggest a level of change in land ownership due to selling and buying practices, which can affect parent's preferences. Furthermore, land quality varies significantly across the region focused on in our analysis. Older farmers own land of better quality and closer to a main road, whereas new farmers are pushed to worse quality land. This implies differences in land accessibility and soil quality. Empirical evidence by Carneiro (2001) corroborates the importance of land quality on parents' behavior towards land division. According to the author, farmers in less productive areas practice an equal division of land, whereas those in more productive areas follow a fixed unequal division rule. In the next section, we present our theoretical model of land inheritance based on the framework of choice under uncertainty.

\section{THE MODEL}

We propose a theoretical model for bequests based on the notion of uncertainty as in Savage (Savage, 1964). We assume that parents assign subjective probabilities for the children's returns, anticipating an exogenous prior. We develop two different models. In the first (unilateral transfers), the child derives utility by his/her own consumption and the transfer received. In the second (bilateral transfers), a service is provided by the child to the parent; this service enters both the parent's and the child's objective function.

\subsection{Unilateral transfers}

Suppose that a parent has two children and lives for two periods. In the first period the parent chooses optimal consumption and investment. In the second period the parent makes a decision about the 
amount of wealth to bequeath, consuming the remaining wealth by his/her death ${ }^{4}$. A subjective prior established by the parent characterizes the return to each child's land-specific human capital. These priors are of common knowledge. This is a sufficient condition to define the expected returns of an offspring's investment in land-specific human capital. ${ }^{5}$ Consider $y=\left(y_{p}, y_{j}, y_{k}\right)$ and $a=\left(a_{p}, a_{j}, a_{k}\right)$ representing the income and optimal investment profile of parent $p$ and the two children, $j$ and $k$, respectively. All agents have the same strictly concave utility function $u: \mathbb{R}_{+} \rightarrow \mathbb{R}$, representing the benefit for each consumption level. This implies that agents are risk averse, in contrast to Chang (2007) which assumes that siblings are risk neutral. For the sake of simplicity, we assume that there is a single numeraire good, that is, the amount of consumption and savings are given in units of this good.

Write $t_{i}$ as the optimal bequest from the parent to the child $i=j, k$. The value function of child $i$ 's problem is given by

$$
v_{i}\left(t_{i}\right)=\max \left\{u\left(c_{i}\right)+\beta \int_{\mathbb{R}_{+}} u\left((1+r) a_{i}+t_{i}\right) f_{i}(r) \mathrm{d} r \mid c_{i}+a_{i} \leq y_{i}\right\}
$$

and the corresponding choices given by

$$
\left(\hat{c}_{i}\left(t_{i}\right), \hat{a}_{i}\left(t_{i}\right)\right)=\arg \max \left\{u\left(c_{i}\right)+\beta \int_{\mathbb{R}_{+}} u\left((1+r) a_{i}+t_{i}\right) f_{i}(r) \mathrm{d} r \mid c_{i}+a_{i} \leq y_{i}\right\},
$$

where $f_{i}$ is the density function inducing the subjective probability of returns and $\beta$ the intertemporal discount rate characterizing the agent's impatience. The parameter $\beta$ is also related to the marginal saving rate ${ }^{6}$. Lemma A. 1 in the Appendix shows that $v_{i}$ is strictly concave for $i=j, k$.

Consider $\mu$ the parameter representing a parent's utility discount relative to the child's utility. A risk-free asset with returns $r_{p}$ is available for the parent. The problem of the parent $p$ is given by

$$
v_{p}=\max \left\{u\left(c_{p}\right)+\beta u\left(\left(1+r_{p}\right) a_{p}-t_{j}-t_{k}\right)+\mu v_{j}\left(t_{j}\right)+\mu v_{k}\left(t_{k}\right)\right\},
$$

where the max is evaluated over all $\left(c_{p}, a_{p}, t_{j}, t_{k}\right) \in \mathbb{R}_{+}^{4}$ such that $c_{p}+a_{p} \leq y_{p}$ and $t_{j}+t_{k} \leq\left(1+r_{p}\right) a_{p}$. In (3), $t_{j}$ and $t_{k}$ represent the transfers for child $j$ and $k$, respectively.

This model predicts larger bequests to the child with the highest subjective expected return to landspecific human capital. This prediction contradicts the altruistic behavior. In order to show this, we provide certain conditions on the child's optimal investment strategies and on the densities $f_{j}, f_{k}$ such that the child with the highest return must receive the largest transfer.

To assure this result we establish two assumptions. Assumption 3.1 below assumes that the child with the lowest return always invests a strictly positive amount on land-specific human capital under the optimal choice. ${ }^{?}$

Assumption 3.1. Let $\hat{a}_{j}, \hat{a}_{k}$ be given by (2). There exits a constant $\bar{a}_{k}>0$ such that $\hat{a}_{k}(t) \geq \bar{a}_{k}$ for all $t \in \mathbb{R}_{+}$.

\footnotetext{
${ }^{4}$ For the sake of simplicity we use a two-period instead of a three-period model. Ideally, parents should pass on the land after their death. In our model, however, they bequeath their goods in the second period. This assumption does not alter our predictions and numerical solutions.

${ }^{5}$ The model described in Altonji et al. (1997) contemplates uncertainty on income only, not on the children's return, as is assumed in our model. Our assumption allows us to isolate the direct effect of land-specific human capital's return on bequests. This was not done by any of the models revised in the literature.

${ }^{6}$ This concept is not considered in the theoretical literature on private transfers.

${ }^{7}$ Under this assumption, the more productive child also invest a positive amount because he/she has a higher return than his/her sibling.
} 
Assumption 3.2 states that the expected value of the marginal benefit for the more productive child at his/her maximum second period consumption level is still higher than the less productive child's at his/her minimum second period consumption level. Thus, even when consumption is at its maximum for the more productive child he/she still has a propensity to save, rendering an expected marginal benefit higher than the one for his/her sibling.

Assumption 3.2. Consider $\bar{a}_{k}$ the constant given in Assumption 3.1 and write $y=\max \left\{y_{j}, y_{k}\right\}$. The subjective densities $f_{j}, f_{k}$ satisfy

$$
\int_{\mathbb{R}_{+}} u^{\prime}((1+r) y+t) f_{j}(r) \mathrm{d} r>\int_{\mathbb{R}_{+}} u^{\prime}\left((1+r) \bar{a}_{k}+t\right) f_{k}(r) \mathrm{d} r \quad \text { for all } t \in \mathbb{R}_{+} .
$$

The following result exhibits certain conditions that favor a non-altruistic behavior. Intuitively, Assumption 3.2 assures that child $j$ has higher expected returns.

Theorem 3.3. Suppose Assumptions 3.1 and 3.2. Then, the optimal transfers $t_{j}^{*}, t_{k}^{*}$ must satisfy $t_{j}^{*}>t_{k}^{*}$.

Proof: See appendix.

\subsection{Bilateral transfers}

Suppose now that the children provide services to the parent as in Bernheim et al. (1985) and Chang (2007). In this case, the environment of friction between family members can be described as a game. Children keep private information on some of their own characteristics due to two credible threats of the parent. One of those relates to the largest transfer that would be made to the most productive child; the other relates to the smoothing of wealth among siblings. We assume that the parent knows his/her children's indirect utility, but not their investment strategies in human capital. In this sequential game, the parent announces a transfer rule conditional on the level of services provided by each child. Thus, each child provides the assistance that maximizes his/her own benefit. This approach is, in essence, similar to that adopted by Faith (2001). Faith assumes that parents partition their inheritable wealth into inter-vivos gifts and bequests. Siblings may compete to engage in rent-seeking to move wealth from the "inter-vivos gifts pool" to the "bequest pool," or vice versa, depending on their relative shares in the two pools.

Consider $y=\left(y_{p}, y_{j}, y_{k}\right)$ and $a=\left(a_{p}, a_{j}, a_{k}\right)$ as the income and optimal investment profile of parent $p$ and the two children, $j$ and $k$, respectively. The amount of consumption and saving is given in units of the single good. Write $t_{i}$ as the bequest from the parent to the child $i=j, k$. This variable may depend on the amount of services provided by the child. The variable $s_{i}$ represents the amount of service supplied by the child $i$ to the parent measured as an opportunity cost. Children have the same concave utility function $u_{i}: \mathbb{R}_{+}^{2} \rightarrow \mathbb{R}$, with $u_{i}\left(c_{i}, s_{i}\right)$ representing the benefit of a consumption level $c_{i}$ and supplied services $s_{i}$. A representative parent has a concave utility function $u_{p}: \mathbb{R}_{+}^{3} \rightarrow \mathbb{R}$, with $u_{p}\left(c_{p}, s_{j}, s_{k}\right)$ yielding the benefit of a consumption level $c_{p}$ and a profile $\left(s_{k}, s_{j}\right)$ of services received from the children. We assume that services generate disutility for the children and utility for the parent, that is, $\partial_{s_{i}} u_{i}\left(c_{i}, s_{i}\right)<0$ and $\partial_{s_{i}} u_{p}\left(c_{p}, s_{j}, s_{k}\right)>0$ for $i=j, k$. As in the previous section, the utility defined only for consumption is given by a concave differentiable $u: \mathbb{R}_{+} \rightarrow \mathbb{R}_{+}$. We consider utility functions separable on consumption and services, that is, $u_{i}\left(c_{i}, s_{i}\right)=u\left(c_{i}\right)+\bar{u}_{i}\left(s_{i}\right)$ for $i=j, k$ and $u_{p}\left(c_{p}, s_{j}, s_{k}\right)=u\left(c_{p}\right)+\bar{u}_{p}\left(s_{j}, s_{k}\right), \bar{u}_{i}: \mathbb{R}_{+} \rightarrow \mathbb{R}_{+}$for $i=j, k$ and $\bar{u}_{p}: \mathbb{R}_{+}^{2} \rightarrow \mathbb{R}_{+}$satisfying the Inada conditions. A risk-free asset with return $r_{p}$ is available for the parent.

The value function of child $i$ 's problem is then given by

$$
v_{i}\left(t_{i}\right)=\max \left\{u_{i}\left(c_{i}, s_{i}\right)+\beta \int_{\mathbb{R}_{+}} u\left((1+r) a_{i}+s_{i} t_{i}\right) f_{i}(r) \mathrm{d} r \mid c_{i}+a_{i}+s_{i} \leq y_{i}\right\}
$$


and the corresponding choices given by

$$
\left(\hat{c}_{i}\left(t_{i}\right), \hat{a}_{i}\left(t_{i}\right), \hat{s}_{i}\left(t_{i}\right)\right)=\arg \max \left\{u_{i}\left(c_{i}, s_{i}\right)+\beta \int_{\mathbb{R}_{+}} u\left((1+r) a_{i}+s_{i} t_{i}\right) f_{i}(r) \mathrm{d} r\right\},
$$

where the max operator is chosen over all $\left(c_{i}, a_{i}, s_{i}\right)$ such that $c_{i}+a_{i}+s_{i} \leq y_{i}$.

Consider $\mu$ the parameter representing a parent's utility discount relative to the child's utility. Write

$$
\tilde{u}_{p}\left(c_{p}, a_{p}, s_{j}, s_{k}, t_{j}, t_{k}\right)=u_{p}\left(c_{p}, s_{j}, s_{k}\right)+\beta u\left(\left(1+r_{p}\right) a_{p}-s_{j} t_{j}-s_{k} t_{k}\right)+\mu v_{j}\left(t_{j}\right)+\mu v_{k}\left(t_{k}\right)
$$

as the parents' utility function. The parent's problem is given by

$$
v_{p}\left(s_{j}, s_{k}\right)=\max \left\{\tilde{u}_{p}\left(c_{p}, a_{p}, s_{j}, s_{k}, t_{j}, t_{k}\right) \mid\left(c_{p}, a_{p}, t_{j}, t_{k}\right) \in \mathbb{R}_{+}^{4}\right\}
$$

and such that $c_{p}+a_{p} \leq y_{p}$ and $s_{j} t_{j}+s_{k} t_{k} \leq\left(1+r_{p}\right) a_{p}$. The corresponding optimal choice,

$$
\left(\hat{c}_{p}\left(s_{j}, s_{k}\right), \hat{a}_{p}\left(s_{j}, s_{k}\right), \hat{t}_{j}\left(s_{j}, s_{k}\right), \hat{t}_{k}\left(s_{j}, s_{k}\right)\right),
$$

written as $\hat{x}_{p}\left(s_{j}, s_{k}\right)$ is given by

$$
\hat{x}_{p}\left(s_{j}, s_{k}\right)=\arg \max \left\{\tilde{u}_{p}\left(c_{p}, a_{p}, s_{j}, s_{k}, t_{j}, t_{k}\right) \mid\left(c_{p}, a_{p}, t_{j}, t_{k}\right) \in \mathbb{R}_{+}^{4}\right\}
$$

such that $c_{p}+a_{p} \leq y_{p}$ and $s_{j} t_{j}+s_{k} t_{k} \leq\left(1+r_{p}\right) a_{p}$.

The next theorem characterizes the solution for this case. It will be given as a Nash Equilibrium. Its proof is similar to that found in Nash (1951).

Theorem 3.4. There exists a profile of bilateral transfers $\left(t_{j}^{*}, t_{k}^{*}, s_{j}^{*}, s_{k}^{*}\right)$ such that:

$$
s_{j}^{*}=\hat{s}_{j}\left(t_{j}^{*}\right), \quad s_{k}^{*}=\hat{s}_{k}\left(t_{k}^{*}\right), \quad t_{j}^{*}=\hat{t}_{j}\left(s_{j}^{*}, s_{k}^{*}\right), \quad t_{k}^{*}=\hat{t}_{k}\left(s_{j}^{*}, s_{k}^{*}\right) .
$$

\subsection{Examples}

To illustrate our theoretical model of unequal transfers under uncertainty, we show three numerical examples. Examples 3.5 and 3.6 illustrate the model in section 3.1, while Example 3.7 elucidates the model in section 3.2. In the first example, children's returns are quite close implying that the parent transfers more to the child with the lowest return. In the second example, the difference in children's returns to land-specific human capital is very large. In this case, the numerical solution shows that the parent transfers a larger share to the more productive child, increasing the aggregate benefit of the family. We conclude that parents' altruistic behavior depends on the variability of capital returns among their offspring.

In the next example, we show that when the variability of the children's human capital returns is low, the parent behaves altruistically. Intuitively, when children have a low contrast in returns, the smoothing effect prevails since the additional benefit obtained with the consumption smoothing is greater than the gain obtained by the additional investment in the more productive child.

Example 3.5. Suppose that $\beta=1 / 2, y_{p}=y_{j}=y_{k}:=y$, and $\mu=1 / 2$. The probability distributions of returns are induced by the densities $f^{j} \sim U[0,0.6]$ and $f^{k} \sim U[0,0.5]$. Under these distributions the expected values of returns are given by 0.3 and 0.25 , respectively. In the case of identical preferences with the utility function given by $u(c)=y \frac{c}{2}-c^{2}$, the optimal choices and bequests, conditional to some specific income level $y$, are ${ }^{8}$

$$
c_{j}\left(t_{j}\right)=0.3495 t_{j}+0.5094 y \quad c_{k}\left(t_{k}\right)=0.3488 t_{k}+0.4942 y
$$

\footnotetext{
${ }^{8}$ All of the following examples were calculated using the software Mathematica.
} 


$$
\begin{aligned}
a_{j}\left(t_{j}\right) & =-0.3495 t_{j}+0.4906 y & a_{k}\left(t_{k}\right) & =-0.3488 t_{k}+0.5058 y \\
t_{j} & =0.2364 y & t_{k} & =0.2385 y
\end{aligned}
$$

Observe that child $k$ has the lowest expected return on his/her investment and receives the largest bequest. In the next example, the variability on returns to human capital is larger enough so that the transfers do not favor altruistic parental behavior.

Example 3.6. Suppose that $\beta=1 / 2, y_{p}=y_{j}=y_{k}:=y$, and $\mu=1 / 2$. The probability distributions of returns are induced by the densities $f^{j} \sim U[0,1]$ and $f^{k} \sim U[0,1 / 2]$. Under these distributions, the expected values of returns are given by 0.5 and 0.25 , respectively. In the case of identical preferences with utility function given by $u(c)=y \frac{c}{2}-c^{2}$, the optimal choices and bequests, conditional to some specific income level $y$, are

$$
\begin{aligned}
c_{j}\left(t_{j}\right) & =0.3461 t_{j}+0.5673 y & c_{k}\left(t_{k}\right) & =0.3488 t_{k}+0.4941 y \\
a_{j}\left(t_{j}\right) & =-0.3461 t_{j}+0.4326 y & a_{k}\left(t_{k}\right) & =-0.3488 t_{k}+0.5058 y \\
t_{j} & =0.2415 y & t_{k} & =0.2356 y
\end{aligned}
$$

Observe that child $j$ has a greater expected return on his/her investment and receives the largest bequest. In the last example, children behave strategically by providing services to the parent.

Example 3.7. Suppose that $\beta=1 / 2, y_{p}=y_{j}=y_{k}:=5$, and $\mu=9 / 10$. The utility function of the children is identical and given by $u\left(c_{i}\right)=20 c_{i}-c_{i}^{2}$ and their utility for services is given by $\bar{u}_{i}\left(s_{i}\right)=-s_{i}$ for $i=j, k$. The utility function of the parent is given by $u\left(c_{p}\right)=20 c_{p}-c_{p}^{2}$ and his utility for services given by $\bar{u}\left(s_{j}, s_{k}\right)=s_{j}+s_{k}$. A risk-free asset with return $r_{p}=9 / 10$ is available for the parent. The probability distributions of returns are induced by the densities $f^{j} \sim U[0,1]$ and $f^{k} \sim U[0,0.75]$. Under these distributions, the expected values of returns are given by $E\left[r_{j}\right]=0.5$ and $E\left[r_{k}\right]=0.325$, respectively. In this case, the optimal choices and bequests are

$$
\begin{aligned}
& c_{j}\left(t_{j}\right)=3.909 \\
& c_{k}\left(t_{k}\right)=4.389 \\
& a_{j}\left(t_{j}\right)=1.092 \\
& t_{j}=0.122 \\
& \begin{aligned}
a_{k}\left(t_{k}\right) & =0.611 \\
t_{k} & =0.122
\end{aligned} \\
& s_{j}=1.474 \\
& s_{k}=7.994
\end{aligned}
$$

Observe that child $k$ has the lowest expected return on his/her land-specific human capital investment and receives the largest bequest since $t_{j} s_{j}<t_{k} s_{k}$.

Note that $t_{j}=t_{k}$ reinforces the result given in Chang (2007). Chang (2007) states that parents choose to split their bequests equally between their children, regardless of earnings differentials across the children. This behavior can be explained by the fact that rent seeking among children generates disutility for the parent. In this case, the loss is not compensated by the return provided by the most productive child since the less productive child has incentive to provide services to offset the potential reduction of his/her inheritance.

\section{EMPIRICAL ANALYSIS}

In this section, we employ novel longitudinal data in the rural Brazilian Amazon to explore the relationship between our theoretical model and patterns in land inheritance among smallholders. Because of the longitudinal aspect of our data, we are able to compare actual and intended behavioral patterns, validating the use of intended bequests in a model where agents live for only two periods.

The Brazilian civil law regarding inheritance posits that wealth must be divided equally after a parent's death in case the disposition option is not evoked in the will. At most $25 \%$ of the total wealth can be used for unequal sharing, which relaxes the legal restriction to equal division of wealth (Pereira, 
2004). This is important because the intention to bequeath or the actual bequest are not fully enforced or determined by law. Furthermore, the study area from where the data was collected is a frontier area in the Brazilian Amazon. This location has less direct government and market intervention, which likely yields non-standard choices as induced by the general inheritance principle of the law.

Our approach differs from previous literature on private transfers as in Stiglitz (1969), Becker (1974), Bernheim et al. (1985), Altonji et al. (1997), McGarry (1999), Stark and Zhang (2002), and Baker and Micelli (2005) in the following aspects. First, we assume that uncertainty will be given on a latent variable representing the returns to land-specific human capital, such as agricultural skills; Altonji et al. (1997) and McGarry (1999) instead assume uncertainty on the future permanent income. Second, we suppose that unequal transfers ${ }^{9}$ can be explained by many factors, including endogenous sharing rules for the bequeatable wealth, contrasting to the exogenous rules assumed by Altonji et al. (1997) and Baker and Micelli (2005). These sharing rules are given as the result of strategic interactions between parents and children, with the latter providing services to maximize their share in the bequeatable wealth. There are few empirical papers testing behavioral models of private transfers because of a lack of quality data (Bernheim et al., 1985; Cox \& Rank, 1992; Schoeni, 1997). The few studies that have been performed are mostly concentrated in developed countries (Arrondel \& Masson, 2006; VanWey \& Nelson, 2007). Despite its important role on consumption smoothing in developing countries where a social welfare system is not fully developed, little is known about patterns of transfers in Latin America (De Vos, 1987) and, specially, in Brazil (Carneiro, 2001; Saad, 1988; VanWey \& Cebulko, 2007).

Our empirical results do not support altruistic behavior for bequests in two ways. First, the majority of intended bequest follows an equal division. Second, most of the significant variables for the probability of unequal sharing suggests that parents favor their children with the highest level of landspecific human capital. The striking prevalence of equal division of land among offspring must be a result of strong constraints that arise from the Brazilian legal system of equal inheritance. The lack of evidence supporting altruistic behavior for bequests is associated with a developed frontier settlement area, where smallholders have strategically consolidated the use of land. In the case of a property specialized in cocoa production, where investment requirements are high and paid back after approximately 25 years, the child with the best ability to continue the land use strategy should receive the largest share of the land. Risk averse landowners would then use the possibility that is opened with the disposition criterion in the Brazilian legislation to model their intention. For instance, if a parent has five children with one of them best suited for continuing cocoa production, he could transfer $15 \%$ for each children and additionally $25 \%$ to the best suited child.

\subsection{Description of the data}

We test our model on a government sponsored settlement project in the rural area of Altamira, in the state of Pará, Brazil. Our study site comprises a total area of 404.700 hectares, located $740 \mathrm{~km}$ away from Belém, the state capital, crossed by the Xingu River from North to South and by the Transamazon Highway from East to West (see Figure 1).

The rural area under study has some important characteristics that need to be stressed. Altamira is a relatively recent settlement frontier area. The Brazilian Government, through its National Institute of Colonization and Agrarian Reform, established a grid of small farm units (about 100 hectares) along the Transamazon Highway. All of the properties have their front to a road (called Travessão), or to the Transamazon Highway, in spite of considerable variation in soil fertility and accessibility during the rainy season along the site. The small size units were designed to incentivize family agriculture and small scale cattle ranching, although land use specialization has been observed in some farms (Guedes et al., 2012; VanWey, D’Antona, \& Brondízio, 2007). Land quality and land use specialization may affect

\footnotetext{
${ }^{9}$ The actual transfer is not directly observed. We estimate it by means of the probability of transferring the land unequally as in McGarry (1999) and Baker and Micelli (2005).
} 
the way the parent evaluates their children's return to land-specific human capital, altering the sharing rule for the land.

The Altamira dataset is part of a larger NIH-funded project, entitled Amazonian Deforestation and the Structure of Households (NIH \#R01-HD35811-09). The project was led by the Department of Anthropology at the University of Indiana in collaboration with the Department of Demography at the State University of Campinas, Brazil. Data was first collected in 1997/1998, with a follow-up survey being conducted in 2005. During the first wave, 402 households on different pieces of land were sampled, being stratified by cohorts of settlement ${ }^{10}$. The researchers interviewed the head of the household, the spouse, and any other women at the property aged 15 and over. The 2005 follow-up was aimed at three groups present in the first wave: a) same couples interviewed in 1997/1998; b) other households located on the same piece of land sampled in the first wave, and c) children of the couples interviewed in 1997/1998 who were living in their own households in 2005.

\subsection{Analytical Samples}

In order to understand the behavior of farmers related to land transmission, we analyze the group of land owners in 1997/1998 who still held the property title in 2005 . We were able to identify what the property owners intended to do with the land in the future for both waves of data.

We divided the observations into two groups: effective bequest (for the former owners who died between 1997/1998 and 2005 and for the ones who passed on the land during the period of analysis) and intended bequests (the future plan for the land reported in 2005 by those holding the title during the period). For the group of deceased farmers, we compare what happened to their land after death with their intentions in 1997/1998. We also conducted the same analysis for the children who effectively inherited the land sometime between 1997 and 2005. This comparison between effective and intended bequest was used to justify behavioral consistency between what is said and what has been done about land inheritance in our study area.

From the 402 farms interviewed in 1997/1998, 399 recorded the farm's owner as the person responsible for the land. In the other three cases, a child was considered the owner. In 2005, 22 out of 399 former owners had died. From the 377 surviving former owners, 315 still held the property ownership, but only 301 of them where interviewed in 2005.

We developed two models to analyze the land inheritance behavior in the region. The first model corresponds to all former owners who held the property title and were interviewed in 2005 . This model corresponds to the determinants of the intention to pass on the land to the offspring. Approximately 280 out of 301 owners had valid information about the future plan for the land in the 2005 survey. We had to drop one case because of a missing observation on the area of the lot in 1997/1998 and six additional cases of households with no children. The final sample used in the study had 273 valid cases.

The second model analyzes the determinants of intended unequal land division. From the $280 \mathrm{ow}$ ners with valid information about the future plans for their land, 180 wanted to pass on the property to their offspring. We dropped one unit because of a missing observation on the land size in 1997/1998. Eleven more cases were excluded because they consisted of families with less than two children. Additional seven cases were eliminated because of an absence of information about children's age and education used to create intra-siblings age and schooling variance. We focus on families with at least two children, since this is the most interesting setting to study transfers choices. Thus, the final sample was restricted to 161 observations.

\footnotetext{
${ }^{10}$ For more details on sampling strategies see VanWey et al. (2007)
} 
Figura 1. Altamira Study Site, Legally defined Brazilian Amazon Region.

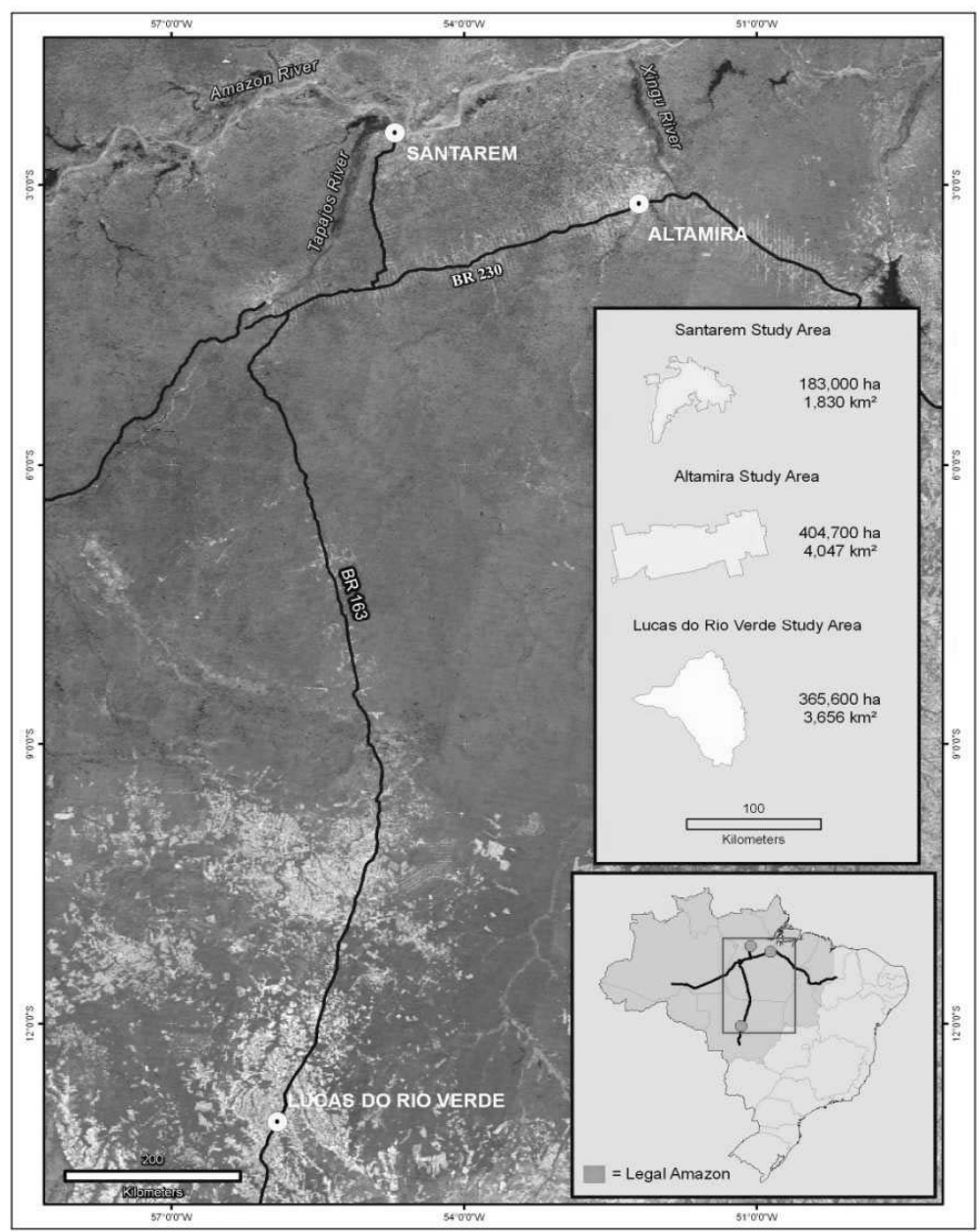

\subsection{Measurement of Dependent Variables}

Because we focus on the circumstances under which the land is divided unequally among the offspring, our primary dependent variable is the intended sharing rule for the land. In both waves of data, land owners where asked about their future plans for the lands they possessed. In the 2005 questionnaire, the following options where listed: a) divide equally among children, b) divide among sons, c) divide among daughters, d) give to a specific child, e) give somehow to children, and f) other plans. These categories were combined to create two different variables: one representing the intention to pass on the land in the future, ${ }^{11}$ the other representing the unequal sharing rule. To create the first dummy variable, categories a) to e) were combined to represent the intention to pass on the land to the children. The second dummy variable, representing the intention to divide the land unequally, was created by combining categories b) to e) against category a). ${ }^{12}$

An important validation step for our primary dependent variable (intended unequal division) was the comparison between reported intentions in 1997/1998 with the actual division observed from 1997/1998

\footnotetext{
${ }^{11}$ This variable was used to estimate the selection equation, as will be explained later in this section.

${ }^{12}$ Category f) was considered incidental truncation.
} 
and 2005. During this period, some land owners died or decided to pass on the land while still alive. As shown in Table 1, in about one-third of the cases for which the owner planned to pass the land to their children, the widow was the beneficiary of the transfer. Another one-third of the properties were divided equally among offspring. In-depth interviews with the deceased former owners back in 1997 were used to qualify their future plans before death. Content analysis indicates that the 19 cases (11 kept by the widow and eight with formal equal division to children) reflected a reported intention of the deceased to follow the equal sharing rule. For the three cases where informal equal division prevailed, the still living parent continued to reside on the farm. Lastly, for the two cases where informal unequal division prevailed, the still living parent moved to an urban area and passed on the land to the male children who already dwelt on the farm and had a long history of connection with the land. These results support our decision to use the future plan reported by the land owners in 2005 as a consistent proxy for actual behavioral decision regarding land inheritance patterns.

In our analytical sample for the first model (intention to pass on the land), 59\% (161) of the owners in 2005 planned to give the land to their children in the future. Among these 161 cases, $26 \%$ (42) declared their intention to divide the property unequally. This is a remarkably high share of unequal bequests for a setting under a legal system that induces equal sharing. Similar levels of an equal bequest were also found in the US in the past (Tomes, 1981).

\subsection{Methods and Estimation}

We focus on the influence of upward transfers, children's liquidity constraints, and land-specific human capital return, as well as the potential of inter-siblings variance on unequal division. Since this model is biased because of sample selection, we performed a two-stage estimation model (Greene, 2003). The first stage corresponds to the selection equation (intention to pass on the land). Then, we generate the Inverse of Mills Ratio and apply it to the model of unequal intended bequest.

In order to estimate the models, we selected a series of variables derived from the survey. We use a woman's reproductive history to generate the children's demographic characteristics. The number of offspring was applied in the models to capture how family size affects the motive to transfer. We also use the number of sons and daughters separately as well as children's age. The gender division allows us to understand gender preferences in land inheritance. Children's age is used as a proxy for the young household life-cycle, which represents a liquidity constraint. We also consider occupation and educational attainment of the offspring as proxies for land-specific human capital investment. The occupation

Tabela 1. Comparison between effective bequest outcomes in 2005 and original future plan of the old owner in 1997/1998 - Altamira Study Area, Pará State, Brazil.

\begin{tabular}{|c|c|c|c|c|c|c|}
\hline \multirow{3}{*}{$\begin{array}{l}\text { Future plan for the land } \\
\text { reported in 1997/1998 }\end{array}$} & \multicolumn{6}{|c|}{ Bequest outcome } \\
\hline & \multirow{2}{*}{$\begin{array}{l}\text { Widow } \\
\text { kept }\end{array}$} & \multicolumn{2}{|c|}{ Equal Division } & \multicolumn{2}{|c|}{ Unequal Division } & \multirow{2}{*}{ Total } \\
\hline & & Formal & Informal & Formal & Informal & \\
\hline Pass on to children & 11 & 8 & 3 & 3 & 2 & 27 \\
\hline Increase the number of properties & 2 & 0 & 1 & 1 & 0 & 4 \\
\hline Other & 1 & 0 & 0 & 0 & 0 & 1 \\
\hline Missing & 1 & 0 & 0 & 0 & 0 & 1 \\
\hline Total & 15 & 8 & 4 & 4 & 2 & 33 \\
\hline
\end{tabular}

Note: the difference between formal and informal is the legal transfer of ownership.

Source: Altamira dataset (1997/1998 and 2005). 
characteristic is especially relevant because it can reveal land-specific human capital investments. For age and schooling, we included the inter-siblings variance in order to test if parents consider the relative distribution of their offspring's return to land-specific human capital when deciding to adopt fixed or unequal rule for an intended bequest.

We also controlled for some of the parent's characteristics. We controlled for parents' health status and educational level. The owner's place of birth was also used to account for the cultural-spatial differences in land transmission, as is argued by Carneiro (2001).

\section{RESULTS}

\subsection{Empirical Exercise}

Table 2 presents summary measures of the data, broken down by endogenous and exogenous variables. The descriptive results show that, on average, $64 \%$ of smallholders intend to pass on the land to their children in the future. Among those, $26 \%$ intend to share it unequally. Children are approximately 20 years old, with five years of schooling, although educational variance is high. About $64 \%$ of male children have a land related occupation, similarly to $65 \%$ for female children. The type of agricultural activity by children's gender, however, differs. While female children are predominantly involved in household chores on the property, such as helping with milking and cheese production, male children are more frequently involved in harvesting, land clearing or more technical tasks. Upward transfers are not uncommon, with $25 \%$ of children helping their parents, mostly with on-the-lot work. Household annual income is about US\$2,309, with an additional US $\$ 1,530$ of equivalent production for self-consumption. This result shows the importance (56\%) of production for self-consumption for household well-being in rural areas. Although most of smallholders have a single property, 30\% have other types of properties, such as another rural lot or urban residence. The average lot allocates $45.6 \%$ of the area for commercial use (pasture and cocoa), with approximately $23 \%$ of those having high-fertility soil. Most of the properties have good accessibility during the rainy season, although road conditions vary considerably throughout the year due to precarious maintenance.

When variables are compared by intention and division rules, interesting differences arise as was predicted by our theoretical model. One interesting finding is the striking difference in land size and soil fertility by sharing rule. As shown in Table 2, the mean area in commercial land use for farmers adopting unequal sharing is $40 \%$ higher than this area for those favoring an equal division of land. Regarding soil fertility, this difference is $52 \%$ higher. These differences are important for our theoretical model, since larger farms and more fertile soils favor unequal sharing by maximizing the parent's utility function.

When the property is small, equal division would prevail in two situations. First, a minimum land size is required to allow small and different agricultural units to be productive if we assume that a threshold for the motivation to divide the land exists. This is exactly what we see from results in Table 2 . Furthermore, for very small farms the impact of the variability in land-specific human capital among children is not enough to trigger unequal sharing. In this situation, the parent prefers to sell the land and equally divide the amount among the offspring. Second, the smaller the land size the smaller the amount $t$ that is transferred to the child, implying that a large contrast between expected children's return is required to satisfy equation (4). Intuitively, the family welfare would be reduced if the parent transferred a marginal unit of wealth from one child to another when both farm size and children's capital return are small. The wealth transferred, in this case, would be represented by an investment in the child's land-specific human capital. This is due to the fact that the marginal utility is decreasing in the total child's wealth. Therefore, a marginal reduction of his/her wealth considerably impacts his/her benefit. In short, even if the land remains productive when fractionated, the effect of smoothing consumption among children in the parent's utility function overlaps the other effects, favoring equal division.

Some children's characteristics also support our theoretical models. For instance, farmers who intend to share the land equally have a $37 \%$ higher probability of being helped by their children than those 
Tabela 2. Descriptive Statistics: mean of explanatory variables-Altamira Study Area, Pará State, Brazil.

\begin{tabular}{|c|c|c|c|c|c|}
\hline Selected Explanatory Variables & $\begin{array}{l}\text { Analytical } \\
\text { sample }\end{array}$ & $\begin{array}{l}\text { Intention to } \\
\text { pass on }\end{array}$ & $\begin{array}{c}\text { Other } \\
\text { intentions }\end{array}$ & $\begin{array}{c}\text { Equal } \\
\text { bequest }\end{array}$ & $\begin{array}{l}\text { Unequal } \\
\text { bequest }\end{array}$ \\
\hline \multicolumn{6}{|l|}{ Children's Characteristics } \\
\hline Mean age & 20.01 & 21.00 & 18.19 & 21.35 & 19.97 \\
\hline Age variance among siblings & 4.66 & 4.76 & 4.48 & 4.72 & 4.87 \\
\hline Mean schooling & 4.57 & 4.71 & 4.32 & 4.67 & 4.81 \\
\hline Schooling variance among sibling & 4.66 & 2.04 & 1.64 & 2.09 & 1.91 \\
\hline Schooling missing (count) & 0.43 & 0.37 & 0.56 & 0.36 & 0.40 \\
\hline Not currently married (count) & 3.20 & 3.31 & 3.00 & 3.33 & 3.24 \\
\hline Married (count) & 2.08 & 2.28 & 1.70 & 2.29 & 2.27 \\
\hline Son with non-agricultural occupation (0/1) & 0.36 & 0.36 & 0.36 & 0.36 & 0.37 \\
\hline $\begin{array}{l}\text { Daughter with non-agricultural } \\
\text { occupation (0/1) }\end{array}$ & 0.35 & 0.39 & 0.27 & 0.38 & 0.43 \\
\hline Upward transfer $(0 / 1)$ & 0.25 & 0.28 & 0.21 & 0.30 & 0.22 \\
\hline Living in the same household (count) & 2.51 & 2.51 & 2.52 & 2.63 & 2.18 \\
\hline Living on the same lot (count) & 0.29 & 0.34 & 0.20 & 0.32 & 0.42 \\
\hline Living off the lot (count) & 2.70 & 2.90 & 2.35 & 2.79 & 3.22 \\
\hline \multicolumn{6}{|l|}{ Parents' Characteristics } \\
\hline $\begin{array}{l}\text { Form of land acquisition } \\
\text { (1-won/0-bought) }\end{array}$ & 1.4 & 1.4 & 1.3 & 1.4 & 1.5 \\
\hline Household annual income (Brazilian R\$) & $5,104.8$ & $5,710.4$ & $3,964.0$ & $4,046.7$ & $10,620.4$ \\
\hline $\begin{array}{l}\text { Monetized annual prod. for self-cons. } \\
\text { (Braz. R\$) }\end{array}$ & $3,381.3$ & $3,128.7$ & $3,857.1$ & $3,017.1$ & $3,457.9$ \\
\hline $\begin{array}{l}\text { Has another property(ies) in the region? } \\
(0 / 1)\end{array}$ & 0.3 & 0.3 & 0.3 & 0.4 & 0.2 \\
\hline Is father sick? (0/1) & 0.2 & 0.2 & 0.2 & 0.2 & 0.3 \\
\hline Is mother sick? (0/1) & 0.2 & 0.2 & 0.2 & 0.1 & 0.3 \\
\hline Father's age (years) & 51.2 & 53.3 & 47.5 & 53.5 & 52.7 \\
\hline Father is illiterate $(0 / 1)$ & 0.2 & 0.2 & 0.2 & 0.2 & 0.2 \\
\hline Father has primary education $(0 / 1)$ & 0.6 & 0.7 & 0.6 & 0.7 & 0.7 \\
\hline Father has secondary education (0/1) & 0.1 & 0.1 & 0.2 & 0.1 & 0.2 \\
\hline Mother has secondary education $(0 / 1)$ & 0.2 & 0.2 & 0.2 & 0.2 & 0.3 \\
\hline Area in pasture (ha) & 40.1 & 44.7 & 31.9 & 41.9 & 53.0 \\
\hline Area in сасаo (ha) & 5.5 & 6.5 & 3.6 & 4.7 & 11.8 \\
\hline Rest of lot area (ha) & 63.5 & 65.3 & 60.1 & 68.8 & 55.3 \\
\hline Year of acquisition (year) & $1,982.7$ & $1,981.4$ & $1,985.0$ & $1,981.6$ & $1,980.8$ \\
\hline Area with high-fertility soil (\%) & 22.6 & 24.3 & 19.5 & 21.4 & 32.7 \\
\hline Land accessible during rainy season $(0 / 1)$ & 0.8 & 0.8 & 0.8 & 0.8 & 0.8 \\
\hline $\begin{array}{l}\text { Distance to Medicilândia urban center } \\
(\mathrm{km})\end{array}$ & $35,064.6$ & $34,031.3$ & $36,477.9$ & $34,568.1$ & $32,467.6$ \\
\hline
\end{tabular}

Source: Altarmira dataset (1997/1998; 2005) 
intending to share unequally. The same pattern emerges when we look at the association between children's place of residence and the sharing rule. While $51 \%$ of the children live in the same household among those parents intending to divide the land equally, this proportion is $12 \%$ lower among parents who plan to distribute their property unequally. The opposite holds for the proportion of children living on the lot, which signals a child's investment in land-specific human capital. While these results are in accordance with our theoretical model, they are bivariate associations. Thus, we turn now to multiple regression associations.

All independent variables are measured in 1997, while the dependent variable is measured in 2005, thus reducing potential bias caused by simultaneity. Because of the potential sample selection in our regression model for unequal sharing, we used a Heckman Selection Probit model. The Likelihood Ratio test of independent equations was not significant ( $p$-value $=0.8745$ ). Thus, we interpret results based on a traditional Probit model with correction for heteroskedasticity (Huber-White variance sandwich estimator). In addition, we use one-tail hypotheses testing because we derive the effect signs from our theoretical models. Table 3 renders statistical support for the main variables from our theoretical model. As shown in Figure 2, the increase in the number of children up to five reduces the probability of unequal sharing by increasing the marginal utility of children's wealth. This effect favors parent's intentions to smooth their children's consumption. For families with more than five children, further increase in family size favors unequal sharing. This is due to the fact that larger family size favors high contrast on returns in land-specific human capital. Properties with larger proportions dedicated to commercial agriculture are more likely to be divided unequally because of the reduction in the child's marginal utility of the amount bequeathed. Smallholders with other properties in the region are more likely to divide the land equally among offspring. This may be explained by the ability to use other properties to implement unequal division. Although our proxy for children's service provision is marginally statistically significant using a two-tail test, the one-tail result would be significant ( $\mathrm{p}$-value $=0.044$ ). Thus, parents who receive some help from their children are less likely to favor a specific child, suggesting the ability of these children to compensate for the contrast in an offspring's land-specific human capital return. Coefficients in Table 3 can be readily compared across independent variables because all the measures were standardized to have a zero mean and unit variance.

Tabela 3. Probit and Heckman Probit Regression for Unequal Sharing of Land-Altamira Study Area, Pará State, Brazil.

\begin{tabular}{lcccc}
\hline Variables & Heckman Probit & Probit & \\
\hline Number of surviving children & $-1.164^{*}$ & {$[0.574]$} & $-1.197^{*}$ & {$[0.564]$} \\
Squared number of surviving children & $1.368^{* *}$ & {$[0.549]$} & $1.368^{* *}$ & {$[0.547]$} \\
\% of lot on commercial land use & 0.202 & {$[0.175]$} & 0.175 & {$[0.176]$} \\
Distance to Altamira urban center & $-0.230^{*}$ & {$[0.133]$} & $-0.230^{*}$ & {$[0.133]$} \\
Has another rural lot & $-0.636^{* *}$ & {$[0.266]$} & $-0.631^{* *}$ & {$[0.268]$} \\
Total household annual income & $0.216^{*}$ & {$[0.128]$} & $0.203^{*}$ & {$[0.123]$} \\
Upward transfers (0/1) & $-0.500^{*}$ & {$[0.293]$} & $-0.495^{*}$ & {$[0.290]$} \\
Inverse of Mills ratio & 1.075 & {$[2.464]$} & & \\
Constant & -0.862 & {$[1.055]$} & $-0.406^{* *}$ & {$[0.168]$} \\
Observations & 161 & & 161 & \\
\hline
\end{tabular}

Note: Robust standard errors in brackets. One-tail test ${ }^{* *} p<0.01,{ }^{*} p<0.05$. Source: Altamira dataset $(1997,1998,2005)$. 
Figura 2. Predicted probability of unequal sharing—Altamira Study Area, Pará State, Brazil.

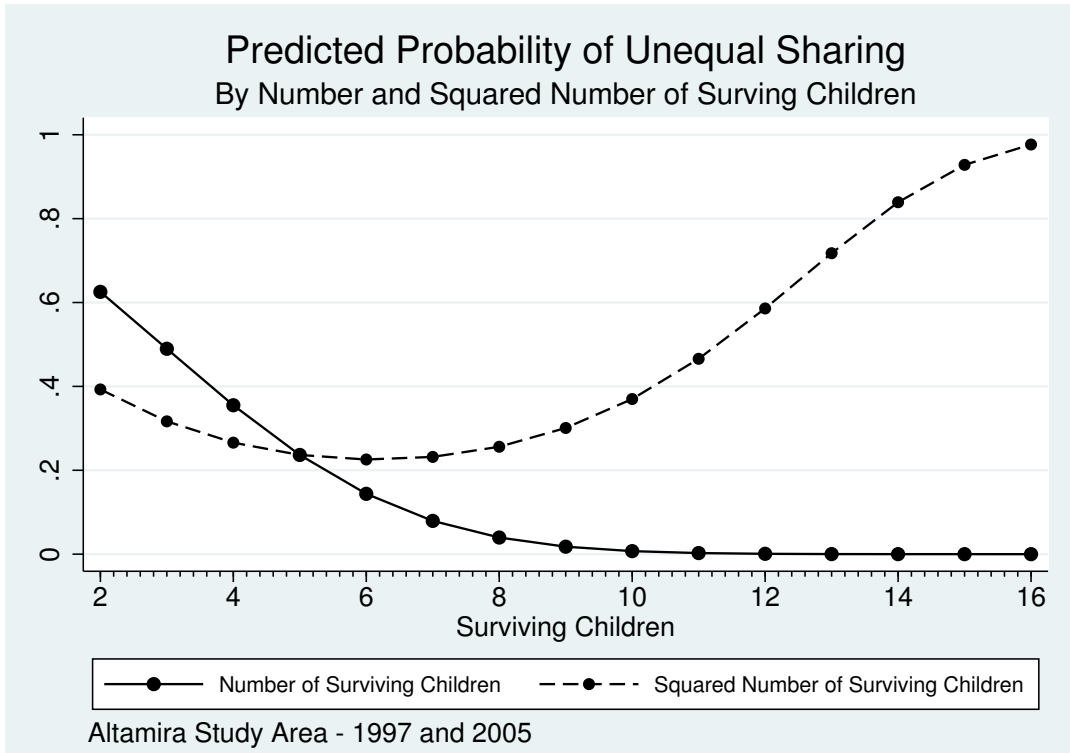

\subsection{Theoretical model}

In the standard altruism model with uncertainty, an increase by one dollar in the income of parents actively making transfers to a child coupled with a one-dollar reduction in that child's income, results in the parents' increasing the transfer to the child by one dollar. The findings of Altonji et al. (1997) strongly reject the altruism hypothesis. Redistributing one dollar from a recipient child to donor parents leads to less than a 13-cent increase in the parents' transfer to the child. This is far less than the one-dollar increase implied by perfect altruism. Our result strengthens this evidence for the case of low levels of marginal utility and large contrasts in land-specific human capital returns. We conclude that an increase by one dollar unit in parents' wealth may not alter the current amount bequeathed to a less productive child. Indeed, an increase in parents' utility due to a transfer of one-dollar to a more productive child can compensate for the reduction of one-dollar in wealth from the less productive child. ${ }^{13}$

Baker and Micelli (2005) discuss two important results on unequal sharing rules, considering the amount of land-specific human capital and abilities for managing the land as distinct parameters. In the first case, they assume scale economies and show that heirs overinvest in land-specific human capital to induce unequal or non-altruistic bequest choices. Consequently, the bequest is entirely awarded to the heir with the higher relative ability to manage the land. The assumption of scale economies, however, does not embody wealth smoothing effects among children. In the second case, the authors assume scale diseconomies and the production function is concave only on the amount of land transferred by the parent. Therefore, the smoothing effects do not incorporate the total wealth from children investment in land-specific human capital.

In our model, we assume that there is a return to the human capital parameter that simultaneously incorporates the ability for managing the land and the land-specific human capital. Parents' utility embodies wealth smoothing effects which are quite robust in the case of high marginal utilities and low contrast in human capital returns among children. Therefore, parents can choose equal or altruistic sharing rules even when assumptions given in Baker and Micelli (2005) are assured, contrasting with their

${ }^{13}$ Obviously, the less productive child has the lower income. 
results. We establish a condition on the parents' priors over land-specific human capital under which the child with the higher expected return receives the largest amount bequeathed. Furthermore, in our model including upward transfers, the equal sharing is a dominant rule regardless of any assumption of heterogeneity in children's land-specific human capital. This also contrasts with the results given in Baker and Micelli (2005).

\section{CONCLUSION}

Building on previous models of private transfers, we developed a theoretical model for intergenerational land transmission in rural settings. We propose an environment where agents live for two periods, considering consumption and investment strategies. Two different approaches were considered. In the first approach, parents make unilateral transfers to their children. In the second approach, children act strategically by providing services to their parents, thus influencing their transferring behavior. Different from Altonji et al. (1997), where uncertainty holds for income only, our model contemplates uncertainty on children's returns to land-specific human capital. The advantage of including uncertainty on returns is to strengthen Altonji et al. (1997)'s result of imperfect altruism and allow for strategic behavior of agents. Indeed, in our first model parents can transfer a larger share of inheritance to the child with the highest relative return among offspring. Our model of unilateral transfers assures that under a certain level of contrasts among children's returns, the child with the largest return will always receive a larger share of the total transfer. This result probes the economic altruism concept, and reinforces the finding of imperfect altruism provided by Altonji et al. (1997).

In the second model, we allow children to behave strategically, as is suggested in Bernheim et al. (1985). Based on a sequential move game, we provided a numerical example in which a parent can potentially choose different transferring amounts. As a result, rent seeking occurs as heirs compete for a larger share of the land. In a Nash equilibrium solution, however, the parent announces equal sharing and waits for his/her children to provide services. This minimizes rent seeking. Under this equilibrium, the less productive child can provide a sufficient amount of services to receive a larger inheritance share, inducing the parent to smooth consumption.

Neither Baker and Micelli (2005) nor Altonji et al. (1997) treated the human capital return as an endogenous variable in the model. This prevented them from establishing conditions on the primitives in order to prove theoretical results, assuring a larger share to the most productive child. Our model, therefore, provides a link between these two models by showing, through the game theory, as in Baker and Micelli (2005) and Bernheim et al. (1985), evidence of non-altruistic behavior as in Altonji et al. (1997). Our numerical and empirical results support the theoretical predictions established by our model. By using primary data on smallholders in an Amazonian frontier, we provide descriptive evidence of equal sharing as a predominant rule, indicating non-altruistic private behavior. Even among those intending to pass on the land unequally, our econometric results suggest that larger shares are more likely to be transferred to more productive children.

\section{REFERENCES}

Altonji, J. G., Hayashi, F., \& Kotlikoff, L. J. (1997). Parental altruism and inter vivos transfers: Theory and evidence. Journal of Political Economy, 105(6), 1121-1166.

Arrondel, L., \& Masson, A. (2006). Altruism, exchange or indirect reciprocity: What do the data on family transfers show? In S. C. Kolm \& J. Mercier-Ythier (Eds.), Handbook on the economics of giving, reciprocity and altruism (Vol. 2, pp. 971-1053). North-Holland: Elsevier. doi: 10.1016/S15740714(06)02014-8

Baker, M., \& Micelli, T. (2005). Land inheritance rules: theory and cross-cultural analysis. Journal of Economic Behavior and Organization, 56(1), 77-102. doi: 10.1016/j.jebo.2003.09.004

Barro, R. J. (1974). Are government bonds net wealth? The Journal of Political Economy, 82(6), 1095-1117. 
Becker, G. (1974). A theory of social interactions. The Journal of Political Economy, 82(6), 1063-1093.

Becker, G., \& Tomes, N. (1979). An equilibrium theory of the distribution of income and intergenerational mobility. The Journal of Political Economy, 87(6), 1153-1189.

Bernheim, B. D., \& Severinov, S. (2003). Bequests as signals: An explanation for the equal division puzzle. Journal of Political Economy, 111(4), 733-764.

Bernheim, B. D., Shleifer, A., \& Summers, L. H. (1985). The strategic bequest motive. The Journal of Political Economy, 93(6), 1045-1076.

Bernheim, B. D., Shleifer, A., \& Summers, L. H. (1986). Bequests as a means of payment (Working Paper No. 1303). National Bureau of Economic Research. doi: 10.3386/w1303

Carneiro, M. J. (2001). Herança e gênero entre agricultores familiares. Revista Estudos Feministas, 9(1), 22-55. doi: 10.1590/S0104-026X2001000100003

Chang, Y.-M. (2007). Transfers and bequests: a portfolio analysis in a Nash game. Annals of Finance, 3(2), 277-295. doi: 10.1007/s10436-006-0050-2

Cox, D. (1987). Motives for private income transfers. Journal of Political Economy, 95(3), 508-546.

Cox, D., \& Jakubson, G. (1995). The connection between public transfers and private interfamily transfers. Journal of Public Economics, 57(1), 129-167.

Cox, D., \& Rank, M. R. (1992). Inter-vivos transfers and intergenerational exchange. The Review of Economics and Statistics, 74(2), 305-314.

De Vos, S. (1987). Latin american households in comparative perspective. Population Studies, 41(3), 501-517.

Faith, R. L. (2001). Inheritance, equal division and rent seeking (ASU Economics Working Paper No. 15/2001). doi: $10.2139 / \operatorname{ssrn} .275973$

Greene, W. H. (2003). Econometric analysis. Pearson Education India.

Guedes, G. R., Brondízio, E. S., Barbieri, A. F., Resende, A., Penna-Firme, R., \& D’Antona, A. O. (2012). Poverty and inequality in the rural Brazilian Amazon: A multidimensional approach. Human Ecology, 40(1), 41-57. doi: 10.1007/s10745-011-9444-5

Hrdy, S. B., \& Judge, D. S. (1993). Darwin and the puzzle of primogeniture. Human Nature, 4(1), 1-45. doi: 10.1007/BF02734088

Keister, L. (2003). Sharing the wealth: The effect of siblings on adults' wealth ownership. Demography, 40(3), 521-542.

Lee, R., \& Mason, A. (2010). Some macroeconomic aspects of global population aging. Demography, 47(1), S151-S172.

McGarry, K. (1999). Inter vivos transfers and intended bequests. Journal of Public Economics, 73(3), 321-351.

Nash, J. (1951). Non-cooperative games. Annals of Mathematics, 54(2), pp. 286-295.

Pereira, C. (2004). Instituições de direito civil: Direitos das sucessões. Rio de Janeiro: Editora Forense.

Saad, P. (1988). Support transfers between the elderly and the family in Southeast and Northeast Brazil (Ph.D. dissertation). The University of Texas, Austin.

Savage, L. (1964). The foundations of statistics. New York: Wiley.

Schoeni, R. F. (1997). Private interhousehold transfers of money and time: New empirical evidence. Review of Income and Wealth, 43(4), 423-448.

Stark, O., \& Zhang, J. (2002). Counter-compensatory inter-vivos transfers and parental altruism: compatibility or orthogonality? Journal of Economic Behavior and Organization, 47(1), 19-25.

Stiglitz, J. E. (1969). Distribution of income and wealth among individuals. Econometrica, 37(3), 382-397.

Tomes, N. (1981). The family, inheritance, and the intergenerational transmission of inequality. Journal of Political Economy, 89(5), 928-958.

VanWey, L. K. (2004). Altruistic and contractual remittances between male and female migrants and households in rural Thailand. Demography, 41(4), 739-756. doi: 10.1353/dem.2004.0039 
VanWey, L. K., \& Cebulko, K. B. (2007). Intergenerational coresidence among small farmers in Brazilian Amazônia. Journal of Marriage and Family, 69(5), 1257-1270. doi: 10.1111/j.17413737.2007.00445.x

VanWey, L. K., D’Antona, A. O., \& Brondízio, E. S. (2007). Household demographic change and land use/land cover change in the Brazilian Amazon. Population and Environment, 28(3), 163-185. doi: 10.1007/s11111-007-004

VanWey, L. K., Guedes, G. R., \& Dantona, A. O. (2012). Out-migration and land-use change in agricultural frontiers: insights from Altamira settlement project. Population and Environment, 34(1), 44-68. doi: $10.1007 / \mathrm{s} 11111-011-0161-1$

VanWey, L. K., \& Nelson, K. (2007). Intergenerational financial transfers from older Americans: Evidence from the Health and Retirement Study. In Proceedings of the Population Association of America.

\section{A. APPENDIX}

Lemma A.1. The value function $v^{i}: \mathbb{R}_{+} \rightarrow \mathbb{R}_{+}$defined by (1) is strictly concave.

Proof: Fix $\alpha>0$. First note that $\hat{c}_{i}(t)+\hat{a}_{i}(t) \leq y_{i}$ for $t \in\left\{t_{i}, t_{i}^{\prime}\right\}$ implies

$$
\alpha \hat{c}_{i}\left(t_{i}\right)+(1-\alpha) \hat{c}_{i}\left(t_{i}^{\prime}\right)+\alpha \hat{a}_{i}\left(t_{i}\right)+(1-\alpha) \hat{a}_{i}\left(t_{i}^{\prime}\right) \leq y_{i} .
$$

Furthermore

$$
v_{i}(t)=u\left(\hat{c}_{i}(t)\right)+\beta \int_{\mathbb{R}_{+}} u\left((1+r) \hat{a}_{i}(t)+t\right) f_{i}(r) \mathrm{d} r \quad \text { for } t \in\left\{t_{i}, t_{i}^{\prime}\right\}
$$

and the concavity of $u$ imply

$$
\begin{aligned}
\alpha v_{i}\left(t_{i}\right)+(1-\alpha) v_{i}\left(t_{i}^{\prime}\right)=\alpha & u\left(\hat{c}_{i}\left(t_{i}\right)\right)+(1-\alpha) u\left(\hat{c}_{i}\left(t_{i}^{\prime}\right)\right) \\
& \quad+\beta \int_{\mathbb{R}_{+}} \alpha u\left((1+r) \hat{a}_{i}\left(t_{i}\right)+t_{i}\right)+(1-\alpha) u\left((1+r) \hat{a}_{i}\left(t_{i}^{\prime}\right)+t_{i}^{\prime}\right) f_{i}(r) \mathrm{d} r \\
\leq & u\left(\alpha \hat{c}_{i}\left(t_{i}\right)+(1-\alpha) \hat{c}_{i}\left(t_{i}^{\prime}\right)\right) \\
& \quad+\beta \int_{\mathbb{R}_{+}} u\left[\alpha\left((1+r) \hat{a}_{i}\left(t_{i}\right)+t_{i}\right)+(1-\alpha)\left((1+r) \hat{a}_{i}\left(t_{i}^{\prime}\right)+t_{i}^{\prime}\right)\right] f_{i}(r) \mathrm{d} r \\
\leq & u\left(\alpha \hat{c}_{i}\left(t_{i}\right)+(1-\alpha) \hat{c}_{i}\left(t_{i}^{\prime}\right)\right) \\
& \quad+\beta \int_{\mathbb{R}_{+}} u\left[(1+r)\left(\alpha \hat{a}_{i}\left(t_{i}\right)+(1-\alpha) \hat{a}_{i}\left(t_{i}^{\prime}\right)\right)+\alpha t_{i}+(1-\alpha) t_{i}^{\prime}\right] f_{i}(r) \mathrm{d} r \\
\leq & v_{i}\left(\alpha t_{i}+(1-\alpha) t_{i}^{\prime}\right)
\end{aligned}
$$

by Equation (A-1) and (1). Clearly, when $t_{i} \neq t_{i}^{\prime}$, the inequations can be chosen strictly because $u$ is strictly concave.

Theorem A.2. Suppose Assumptions 3.1 and 3.2. Then, the optimal transfers $t_{j}^{*}, t_{k}^{*}$ must satisfy $t_{j}^{*}>t_{k}^{*}$.

Proof: Assuming an interior solution, ${ }^{14}$ differentiating with respect to $t_{i}$ and applying the Envelop theorem to equation (1) we get for each $t_{i} \in \mathbb{R}_{+}$

$$
v_{i}^{\prime}\left(t_{i}\right)=\beta \int_{\mathbb{R}_{+}} u^{\prime}\left((1+r) \hat{a}_{i}\left(t_{i}\right)+t_{i}\right) f_{i}(r) \mathrm{d} r \quad \text { for } i=j, k
$$

\footnotetext{
${ }^{14}$ The condition $\lim _{c \rightarrow 0^{+}} u^{\prime}(c)=\infty$ assures the interior optimum.
} 
Moreover, the F.O.C. of equation (3) with respect to $t_{j}, t_{k}$ evaluated on the optimum $\left(a_{p}^{*}, t_{j}^{*}, t_{k}^{*}\right)$ for a interior solution yields

$$
\beta u^{\prime}\left(\left(1+r_{p}\right) a_{p}^{*}-t_{j}^{*}-t_{k}^{*}\right)=\mu v_{i}^{\prime}\left(t_{i}^{*}\right) \text { for } i=j, k \text {. }
$$

Assumptions 3.1, 3.2 and equation (A-2) evaluated on $t_{i}=t_{k}^{*}$ imply that $^{15}$

$$
\begin{aligned}
v_{j}^{\prime}\left(t_{k}^{*}\right) & =\beta \int_{\mathbb{R}_{+}} u^{\prime}\left((1+r) \hat{a}_{j}\left(t_{k}^{*}\right)+t_{k}^{*}\right) f_{j}(r) \mathrm{d} r \\
& \geq \beta \int_{\mathbb{R}_{+}} u^{\prime}\left((1+r) y+t_{k}^{*}\right) f_{j}(r) \mathrm{d} r \\
& >\beta \int_{\mathbb{R}_{+}} u^{\prime}\left((1+r) \bar{a}_{k}+t_{k}^{*}\right) f_{k}(r) \mathrm{d} r \\
& \geq \beta \int_{\mathbb{R}_{+}} u^{\prime}\left((1+r) \hat{a}_{k}\left(t_{k}^{*}\right)+t_{k}^{*}\right) f_{k}(r) \mathrm{d} r \\
& =v_{k}^{\prime}\left(t_{k}^{*}\right)=v_{j}^{\prime}\left(t_{j}^{*}\right) .
\end{aligned}
$$

Therefore we conclude that $v_{j}^{\prime}\left(t_{k}^{*}\right)>v_{j}^{\prime}\left(t_{j}^{*}\right)$. This implies that $t_{j}^{*}>t_{k}^{*}$ since Lemma A.1 assures that $v_{j}$ is concave and hence $v_{j}^{\prime}$ is decreasing.

${ }^{15}$ Observe that in the second and fourth inequality we use that $u^{\prime}$ is decreasing, $\hat{a}_{j}\left(t_{k}^{*}\right) \leq y$ and $\hat{a}_{k}\left(t_{k}^{*}\right) \geq \bar{a}_{k}$. 